\title{
A SOURCE PARAMETERS STUDY OF THE AFTERSHOCK SEQUENCE OF THE KOZANI- GREVENA 1995 EARTHQUAKE BASED ON ACCELERATION RECORDS
}

\author{
Panou A.A. ${ }^{1}$, Papazachos C.B. ${ }^{1}$, Papaioannou Ch. ${ }^{2}$, and Hatzidimitriou P.M. ${ }^{1}$ \\ ${ }^{1}$ Geophysical Laboratory, School of Geology, Aristotle University of Thessaloniki, PO Box 352-1, \\ 54124, Thessaloniki, apanou@lemnos.geo.auth.gr, costas@lemnos.geo.auth.gr, \\ takis@lemnos.geo.auth.gr \\ ${ }^{2}$ Institute of Engineering Seismology and Earthquake Engineering, P.O. Box 53 Foinikas, GR- \\ 55102, Thessaloniki, chpapai@itsak.gr
}

\section{ABSTRACT}

Strong motion recordings of the May 13, $1995 \mathrm{Mw}=6.6$, earthquake sequence that occurred in the Kozani-Grevena region (Western Macedonia, Greece) have been analyzed for the determination of their source parameters. The data set for this study comes from a temporarily deployed accelerograph network and the source parameters using the shear-wave displacement spectra have been estimated. For this estimation the spectral records have been corrected for the site effects and for the propagation path (geometrical spreading and anelastic attenuation). The magnitude of each event was also re-calculated by estimating appropriate station corrections. The derived relationships are

$$
\begin{array}{rlrl}
\log M_{o} & =(1.43 \pm 0.09) & M_{L}+(16.92 \pm 0.29), & 2.0<M_{L}<5.0 \\
\log f_{c} & =(-0.56 \pm 0.08) \cdot M_{L}+(2.52 \pm 0.29), & 2.0<M_{L}<5.0 \\
\log M_{0}=(-2.20 \pm 0.08) \cdot \log f_{c}+(23.16 \pm 0.84), & 0.6<f_{c}<10.0
\end{array}
$$

The near-surface attenuation parameter $\mathrm{K}_{0}$ has also been determined for the strong motion stations sites. These values of $K_{0}$ are in good agreement with those of Margaris and Boore (1998) for the geological formation on which each station was positioned. The obtained source parameters are in good agreement with those from previous studies for the Aegean region.

\section{INTRODUCTION}

A damaging earthquake ( $M w=6.6$ ) occurred on May 13, 1995 in the Kozani - Grevena region. This area has not shown a high level of seismic activity in historical times since only one strong earthquake (896 A.D.), was reported in the historical catalogues (Papazachos and Papazachou, 1997, 2002; Ambraseys, 1999). The earthquake sequence has been extensively studied at every scientific field (Hatzfeld et al., 1995, 1997; Papazachos B. C. et al., 1998; Theodulidis et al., 1998; Papanastasiou et al., 1998; Kiratzi, 1999; Roumelioti et al., 2000, 2002).

In this paper we analyze the complete data set available for the Kozani - Grevena aftershock sequence. A procedure has been applied for the accurate determination of the local magnitude, $M_{L}$, from regional records. The source parameters are obtained by fitting standard spectral shapes to the S-wave spectra and a least-squares' procedure is developed to account for differences between recording stations in order to accurately determine the final source parameters for each event. 


\section{DATA ACQUISITION - EARTHQUAKE LOCATIONS}

One day after the earthquake occurrence, a temporary 3-component digital strong motion array was installed by the Geophysical Laboratory of the Aristotle University of Thessaloniki (GL-AUTh) and the Institute of Engineering Seismology and Earthquake Engineering (ITSAK), to monitor the ground acceleration due to the aftershocks. Accelerographs were also installed by the Seismological Laboratory of Athens University (SL-AU), the Applied Statics Laboratory of the Aristotle University of Thessaloniki (ASL-AUTh) and the LGIT of the Grenoble J. Fourier University (LGIT), (shown in the right part of Figure 1).

For several earthquakes, which triggered at least one accelerograph, the epicenters were not estimated from routine analysis. The location of these events was accomplished using the $P$ and the S-wave arrivals from the temporary seismological network that was installed in the area and from the permanent seismological network of GL-AUTh. Figure 1 (left part) shows a map with the seismological stations of the permanent and temporary network. In the location procedure the appropriate station correction terms were used. These terms represent the contribution of the average crustal and upper mantle structure beneath the receiver and a local layered velocity model, which was estimated for the Kozani-Grevena area (Hatzfeld et al., 1995; Papazachos et al., 1998; Drakatos et al., 1998 ). The S-P times of the temporary accelographs network were also included in the phase list. For the location procedure the HYPO'71 program (Lee and Lahr, 1975) was used. Figure 1 (right part) shows the geographical distribution of the epicenters, determined in the present study (gray circles). The triangles stand for the location of the station.

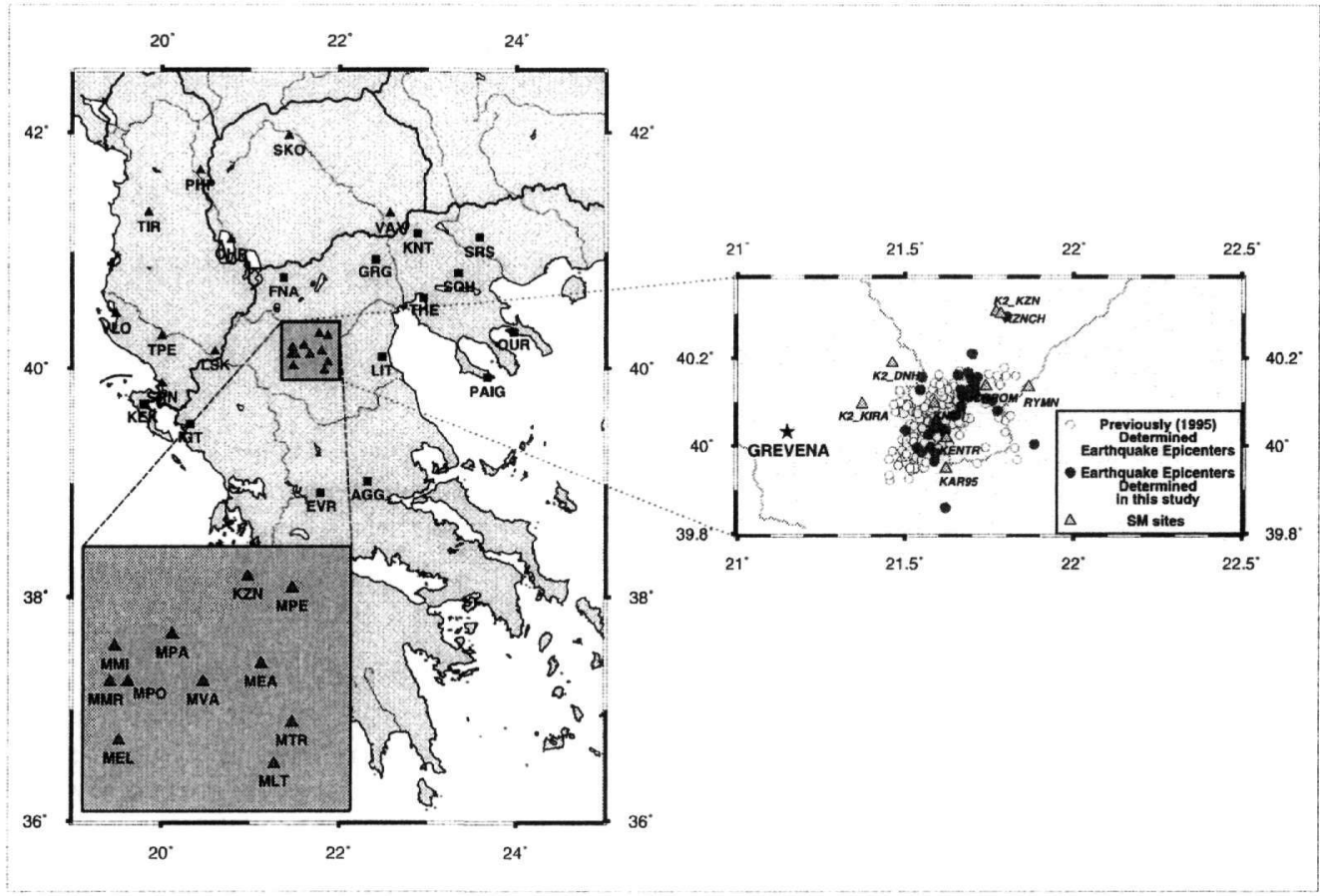

Figure 1. Left part: Map view of the location of the seismological stations. Gray triangles represent the temporary seismological network, while solid squares represent stations of the permanent seismological network. Right part: Locations of the epicenters of the earthquakes that were determined in the present study (solid gray circles), locations of earthquake epicenters determined in previous studies (open circles) and strong motion stations (solid triangles) used in the present study. 


\section{MAGNITUDE ESTIMATION}

An important parameter used for the evaluation of source 'size' is the magnitude of the earthquakes, which is a standard measure of the amount of energy released. Richter (1958) proposed a magnitude scale based on the amplitude traces recorded on the seismograms. For this purpose the analog records of the permanent seismological network of GL-AUTh (LIT, KNT, SRS, THE, THElg, AGG, IGT, FNA and PAIG) were used. We picked the maximum zero-to-peak amplitude, $A$, from $S-$ waves and the duration of the signal of the earthquakes. The relations that were used to determine local magnitude from ground amplitudes, $M_{A}$, are the following

$$
\begin{aligned}
& M_{A}=\log \alpha+1.199 \cdot \log \Delta+1.268+c, \\
& \Delta<100 \mathrm{~km} \\
& M_{A}=\log \alpha+2.32 \cdot \log \Delta-1.07+c,
\end{aligned}
$$

where $\alpha$ (in $\mu \mathrm{m}$ ) is the ground amplitude as inferred from the maximum recorded amplitude $A, \Delta$ is the epicentral distance in $\mathrm{km}$ and $\mathrm{c}$ is the station correction factor. The signal duration, $\mathrm{D}$, (in seconds), which was measured from the P-onset up to $2 \mathrm{~mm}$ peak-to-peak amplitude level (analogue recording by the permanent network) is also used to calculate local magnitude, $M_{D}$,

$$
\begin{array}{ll}
M_{D}=2.14 \cdot \log D+0.0038 \cdot \Delta+c, & \Delta<100 \mathrm{~km} \text { (3) } \\
M_{D}=1.97 \cdot \log D+0.0012 \cdot \Delta+c, & \Delta>100 \mathrm{~km}(4)
\end{array}
$$

where $\Delta$ is the epicentral distance in $\mathrm{km}$ and $\mathrm{c}$ is the station correction. The values of the station correction factors and the coefficients in relations (1) - (4) have been estimated by Kiratzi (1984) and Scordilis (1985) for stations LIT, KNT, SRS, THE, THElg.

Variation in magnitudes of an earthquake reported by different stations are expected to be found due to the radiation pattern, geometrical spreading and anelastic attenuation. However, each earthquake can be considered to have a unique magnitude, $\mathrm{M}_{\mathrm{i}}$, assigned to it. Thus, the magnitude $\mathrm{M}_{\mathrm{i}}{ }^{\mathrm{j}}$ of the ith earthquake recorded at station $\mathrm{j}$ can be given by

$$
M_{i}{ }^{j}=M_{i}+d^{j}
$$

where $d^{j}$ is the station magnitude correction of the $j$ station. Constant $d^{j}$ incorporates all the factors that affect the recordings of an earthquake at different stations. If an earthquake, $i$, has been recorded at $\mathrm{k}$ stations and the magnitude, $\mathrm{M}_{\mathrm{i}}{ }^{\mathrm{j}}$, in $\mathrm{j}$ stations is known, then from equation (5) we obtain a linear system, which includes equations for all earthquakes, which can be written in matrix form as

$$
A x=b
$$

where $b$ is the data vector which contains the magnitudes at every station, $x$ is the vector which contains the unknowns, that is the station corrections $d^{j}$ and the "true" magnitude $M_{i}$ for every earthquake and the matrix $A$ contains the weight factors, $w$, of the data depending on their relative quality. The system was solved in the least squares' sense where the solution has the form

$$
x_{\text {LSQ }}=\left(A^{T} A\right)^{-1} A^{T} b
$$

In order to obtain a unique solution of equations (5), the sum of all stations corrections, $d^{j}$, was assumed to be equal to zero

$$
\sum d^{j}=0
$$

This additional linear constrain practically means that the average magnitude estimated from all stations (if all were available for each event) has zero bias with respect to the "true" earthquake magnitude.

Following the previous procedure the system was solved for three different data sets. In the first one, the local magnitudes $M_{A}$, estimated from equations (1), (2), were used for the estimation of the local magnitude $M_{A(l s)}$. In the second data set the local magnitudes $M_{D}$, estimated using equations (3), (4), were used and the local magnitude $M_{D /(s)}$ was calculated. The trace amplitudes and the signal durations from the analog records of the AGG, IGT, FNA and PAIG were also used to estimate the corresponding local magnitudes $\left(M_{A}\right.$ and $\left.M_{D}\right)$, after the determination of the values of the parameter $c$. The magnitudes from the records of these four stations were merged with the previous two data sets in order to improve the estimation of the local magnitude of the events and a unique local magnitude, $M_{L}$, was obtained with each earthquake. Figure 2 shows a graph that compares this local magnitude $M_{L}$ with local magnitudes estimated with the least-square's process from ampli- 
tudes, $M_{A(/ s)}$ (left part) and signal duration $M_{D(/ s)}$ (right part), showing that there is a good agreement between local magnitude $M_{L}$ and magnitudes $M_{A(l s)}, M_{D(l s)}$.

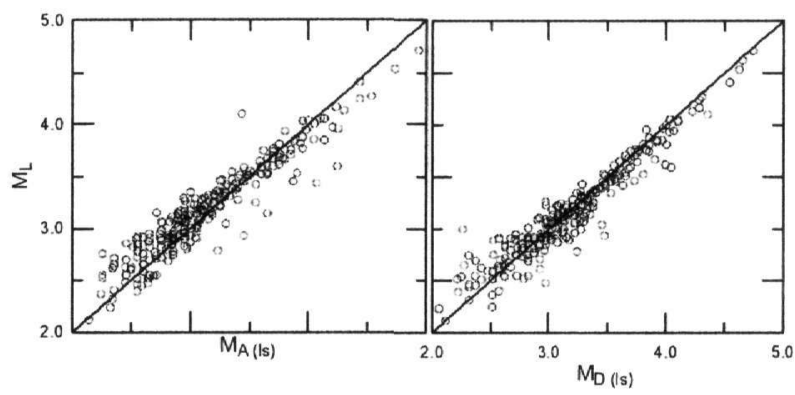

Figure 2. Plot of the local magnitude $M_{L}$ variation versus $M_{A(l s)}$ (left part) and versus $M_{D(l s)}$ (right part).

From Figure 2, it is also clear that the dispersion in $M_{L}=f\left(M_{D /(s)}\right)$ is less than in $M_{L}=f\left(M_{A(l s)}\right)$. This is partly due to the fact that the data from the signal duration were more abundant than the data from maximum zero-to-peak amplitudes but also reflects the greater variability of maximum amplitude compared to the signal duration for the same magnitude and recording distance.

\section{DATA ANALYSIS}

During the operation of the strong motion array more than 600 aftershocks were recorded. A preliminary data selection was preformed mainly involving visual inspection of waveform data. After the baseline correction three time windows have been visually selected containing the noise recorded before the P-wave onset, the P-waves and the S-waves. The S-wave time window was chosen to start immediately before shear waves and end before the coda waves (Archuleta et al., 1982). The Fourier amplitude spectra of the S-waves were computed using the SAC software (Tampley and Tull, 2000) for the three components. The sampling interval for all waveforms was $\Delta t$ $=0.005 \mathrm{sec}$, and the obtained spectra were smoothed using a moving average window of $0.5 \mathrm{~Hz}$ with $50 \%$ overlap. An example illustrating the procedure is shown in Figure 3 (the recording of one horizontal component of the ground acceleration in station K2_KIRA of the earthquake 950517).

\section{MODELING OF SOURCE SPECTRUM}

The estimation of seismic moment, $M_{0}$, and corner frequency, $f_{c_{1}}$ through the spectra of ground motion involves the definition of a theoretical model for the source spectrum. A commonly used source displacement spectral model is that of Brune $(1970,1971)$ which has the form

$$
\mathrm{S}^{\prime}(\mathrm{f})=\Omega_{0} \frac{(2 \pi \mathrm{f})^{2}}{1+\left(\frac{\mathrm{f}}{\mathrm{f}_{\mathrm{c}}}\right)^{2}}
$$

The parameters of this model are the low-frequency spectral level, $\Omega_{0}$, and the corner frequency, $f c$. The low-frequency spectral level, $\Omega_{0}$, is proportional to seismic moment, $M_{0}$, (Keilis-Borok, 1959)

$$
\mathrm{M}_{0}=\frac{4 \pi \rho \cdot \mathrm{v}_{\mathrm{s}}^{3} \Omega_{0}}{\mathrm{kR}_{\theta \varphi}}
$$

where $\rho\left(=2.7 \mathrm{gr} / \mathrm{cm}^{3}\right)$ is the density, $v_{S}$ is the $S$-wave velocity with a value equal to $3.4 \mathrm{~km} / \mathrm{sec}(\mathrm{Pa}$ pazachos C. B. et al., 1998) for the Kozani area, $k$ is a correction factor for free surface reflection and $R_{\theta \varphi}$ is the $S$-wave radiation pattern coefficient. Usually, the product $k R_{\theta \varphi}$ is assumed to have a mean value of 0.85 (Boore and Boatwright, 1984), which was also adopted here.

The ground motion spectrum $D(f, R)$ at a distance, $\mathrm{R}$, from the source can be modeled to incorporate the separable effects of source $S(f)$, propagation $A(f, R)$, site $Z(f)$ and instrument response I(f) 


$$
\mathrm{D}(\mathrm{f}, \mathrm{R})=\mathrm{S}(\mathrm{f}) \cdot \mathrm{A}(\mathrm{f}, \mathrm{R}) \cdot \mathrm{Z}(\mathrm{f}) \cdot \mathrm{I}(\mathrm{f})
$$

From equation (11) it is clear that the observed source spectra can be computed by

$$
S(f)=\frac{D(f, R)}{A(f, R) \cdot Z(f) \cdot I(f)}
$$

Both the theoretical, $S^{\prime}(f)$, and the observed, $S(f)$, source spectra are dependent on two parameters, namely the seismic moment, $M_{0}$, and the corner frequency, $f_{c}$. In the present work the determination of seismic moment, $M_{0}$, and corner frequency, $f_{c}$, were made by the non-linear minimization of the difference between the theoretical and observed spectra (after the correction for site effects and attenuation), $S(f)-S^{\prime}(f)$, in the least-squares' sense using the Levenberg-Marquardt method. Since there is a nonlinear dependence between the model and the unknown parameters the minimization is performed iteratively, using an initial solution.
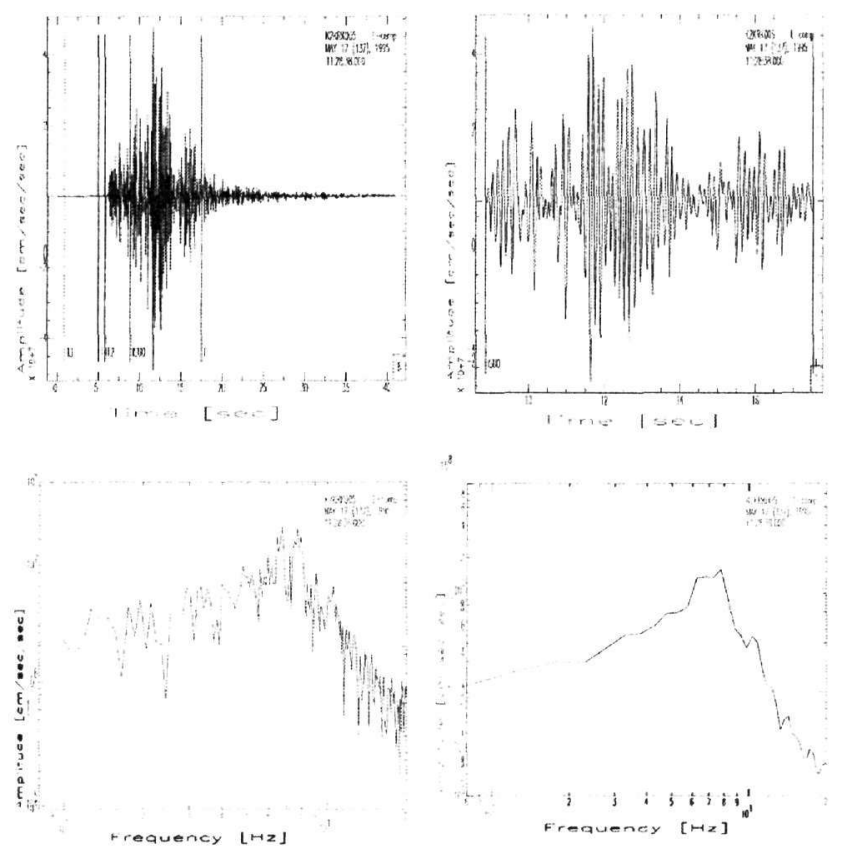

Figure 3. An example of the processing of accelerograms. Upper left: Original acceleration seismogram of one horizontal (Iongitudinal) component of the earthquake 950517 at station K2_KIRA. The vertical lines indicate time window of: noise (T3-T4), P-wave (T3-T4) and S-wave (ISUO-F). Upper right: The S-wave time window adopted. Lower left: The S-wave acceleration spectrum. Lower right: The smoothed S-wave acceleration spectrum.

\section{SITE EFFECT CORRECTION}

For every station the horizontal-to-vertical spectral ratio technique was applied in order to evaluate the local site effects. This technique was introduced by Nakamura (1989), who applied it to noise recordings and showed that the ratio of the Fourier spectra of the horizontal components to the spectrum of the vertical component (transfer function) reveals the soil's principal resonance frequencies. Encouraging results were later obtained from strong-motion recordings (Lermo and Chavez-Garcia, 1993; Theodulidis and Bard, 1995). The result of site effect to seismic motion is approximated by the following equation

$$
Z=\sum \frac{H}{V}=\sum \frac{\sqrt{L^{2}+T^{2}}}{\sqrt{2} V}
$$


where $\mathrm{H}$ is the horizontal component, consisting of the two transverse components $\mathrm{L}$ and $\mathrm{T}$, and $\mathrm{V}$ is the vertical component. Based on equation (13) we calculated the mean transfer function for each of the nine stations.

Figure 4 shows the frequency variation of the mean transfer function for each site (black solid line), while the dashed lines represent the 1- $\sigma$ standard deviation above and below the mean transfer function. Apparently, the site effects in terms of mean spectral ratio vary with location. More specifically, high values of amplification are observed in the range $3-4 \mathrm{~Hz}$ at $\mathrm{RYMN}$, in the range $1-2$ $\mathrm{Hz}$ at KENTR, in the range $0.8-1 \mathrm{~Hz}$ at KAR95. Moreover there are prominent peaks of amplification at $5 \mathrm{~Hz}$ at $\mathrm{CHROM}$, at $6 \mathrm{~Hz}$ at K2_KIRA, and at $4 \mathrm{~Hz}$ at K2_DNH. This observational result illustrated the fact that the geological units under the stations are not the same. In Figure 4 the comparison for two stations (CHROM and KNIDI) of the empirical with the corresponding theoretical mean transfer functions is also shown, as these were estimated by Raptakis et al. (1997) (gray solid line) using the available geophysical-geotechnical information for these sites. The transfer functions given by both different methods are in good agreement hence the $\mathrm{H} / \mathrm{V}$ ratios can be used to approximately correct the strong-motion recordings for site effects, for our study area.
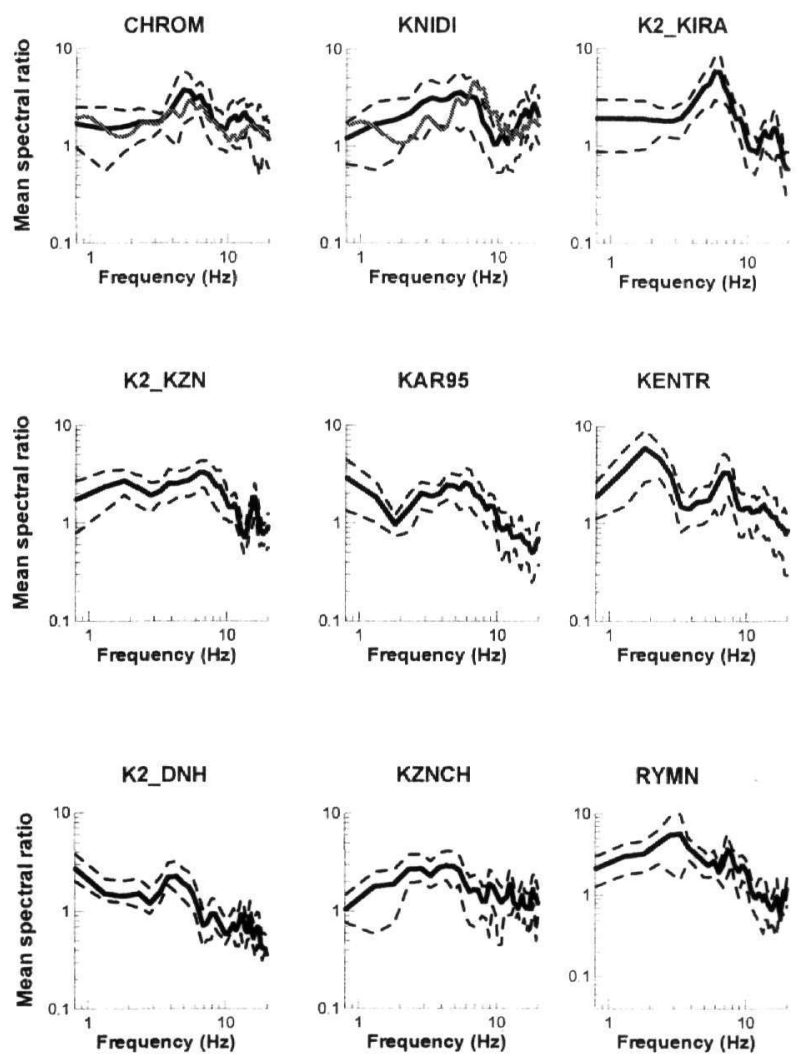

Figure 4. Plot of mean spectral ratio, $\mathrm{HN}$, at each station site (solid line). Standard deviation, dashed lines of \pm $1 \mathrm{SD}$ is also plotted. For the strong motion stations (CHROM and KNIDI) the comparison with the theoretical (Raptakis et al., 1997; grey lines) mean transfer functions is plotted.

\section{ATTENUATION}

An important factor in studying the ground shaking phenomena is the attenuation of seismic waves along their path between the source and the receiver. The parameterisation of propagation is usually represented by the equation 
where

$$
A(R, f)=G(R) \cdot \exp (-\pi \kappa f)
$$

$$
G(R)=R^{-n}
$$

is the geometrical spreading and $R$ is the hypocentral distance. The body-wave amplitude decay due to geometrical spreading is usually assumed to be proportional to $\mathrm{R}^{-1}$. The quantity

$$
\exp (-\pi \kappa f)
$$

is the frequency dependent attenuation function. Anderson and Hough (1984) proposed that the spectral decay parameter, $\mathrm{k}$, for a homogenous half-space, is separated into two components

$$
k=\kappa_{0}+\frac{R}{Q(f) \cdot v_{s}}
$$

where $K_{0}$ is the near-surface attenuation parameter specific to each site (it controls the shape of spectra at high frequencies), $R$ is the distance between the source and the receiver, $Q(f)$ is the quality factor and $v_{S}$ is the $S$ wave velocity. In general $Q(f)$ is observed to be frequency dependent. In the present study we adopted the values of $Q(f)$ reported by Baskoutas et al. (1997), who have found

$$
\mathrm{Q}_{\mathrm{C}}=47 \cdot \mathrm{f}^{1.02}
$$

for the area of Kozani- Grevena using data from coda waves.

From relations (14), (15), (17) and (18) we can derive the final equation that describes the spectral function of the propagation path of S-waves for the study area

$$
A(R, f)=\frac{1}{R} \cdot e^{-\pi \kappa_{0} f} \cdot e^{-\pi R f / 47 f^{1.02} v_{s}}
$$

\section{ESTIMATION OF SOURCE PARAMETERS}

Combination of the theoretical spectral model given by equation (9) and (10), with the observed spectra, results in the following equation

$$
\frac{D(f, R)}{Z(f) \cdot I(f)} \cdot e^{\pi R f / 47 f^{1.02} v_{s}} \cdot R=\frac{k R \theta \varphi \cdot M o}{4 \pi \rho \cdot v_{s}^{3}} \cdot \frac{(2 \pi f)^{2}}{1+\left(\frac{f}{f_{c}}\right)^{2}} \cdot e^{-\pi \kappa_{0} f}
$$

Following the method, described previously, we can simultaneously estimate the seismic moment, $M_{0}$, the corner frequency, $f_{c}$, and the near-surface attenuation parameter $\kappa_{0}$, using the two horizontal components of each S-wave recording at every station.

Parameter $\mathrm{K}_{\mathrm{o}}$ usually accounts for the attenuation due to local site geology and is smaller for strong motion stations located on rock outcrops compared to stations located on either shallow or deep sediment deposits station. Hence it is usually assumed to be specific at every station. Moreover, it is independent of the source - receiver distance (Archuleta et al., 1992; Margaris and Hatzidimitriou, 1997). For this reason, we have estimated the mean value of $\mathrm{K}_{0}$ for all recordings at every station. These values of $k_{0}$ are in good agreement with those of Margaris and Boore (1998), for the geological formation on which each station was positioned (Christaras et al., 1998; Mountrakis et al., 1998; Pavlides 1998, among others).

The obtained values of $\mathrm{K}_{0}$ were used for the data process. Hence, the seismic moment, $M_{0}$, and the corner frequency, $f_{c}$, were recalculated for the S-part of the recordings of the two horizontal components at every station.

\section{RESULTS AND DISCUSSION: COMPARISON WITH OTHER STUDIES}

Figure 5 (left part) shows the estimated $\log M_{0}$, values versus local magnitude, $M_{\mathrm{L}}$. In this figure the results of Chouliaras and Stavrakakis (1997), Margaris and Papazachos (1999), Panagiotou (2001), Polatidis (2001) and Roumelioti et al. (2002), are also presented. Straight lines represent the relation of Margaris and Papazachos (1999), Roumelioti et al. (2002) and the relation defined in 
this study. Wherever the original results were referring to moment magnitude, $M_{w}$, we used the following relation to estimate local magnitude, $M_{L}$

$$
\mathrm{M}_{\mathrm{w}} \cong \mathrm{M}_{\mathrm{L}}+0.5
$$

which is valid for the records of the Greek seismological networks (Papazachos et al., 1997b).
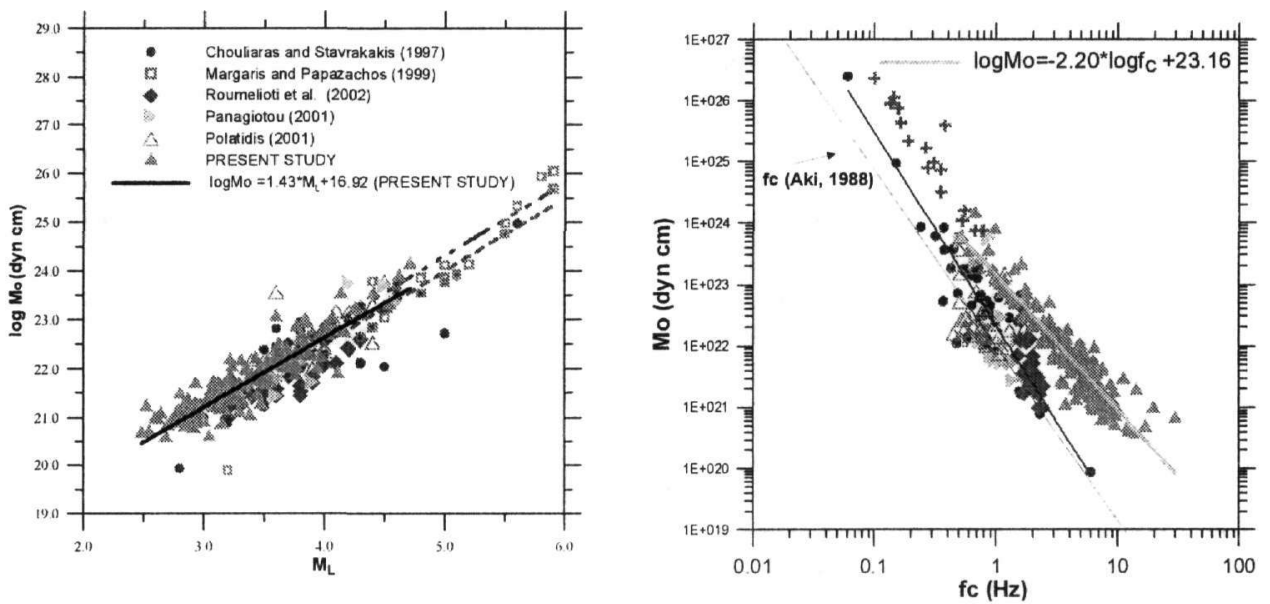

Figure 5. Left Part: Seismic moment, $\mathrm{M}_{0}$, versus $\mathrm{M}_{\mathrm{L}}$ : Comparison between the results derived in the present study and those from Chouliaras and Stavrakakis (1997), (solid circles), Margaris and Papazachos (1999), (open square), Panagiotou (2001), (solid triangle), Polatidis (2001), (open triangles) and Roumelioti et al. (2002), (solid diamond). Black and gray thin lines are equations proposed by Margaris and Papazachos (1999) and Roumelioti et al. (2002), respectively. The black thick line corresponds to equation (1) proposed in this study. Right Part: Seismic moment, $M_{0}$, variation versus corner frequency, $\mathrm{f}_{\mathrm{c}}$. The symbols have the same meaning as in the left part of the figure 1. Black and gray thin lines are relations proposed by Aki (1988) and Chouliaras and Stavrakakis (1997) respectively, while the gray thick line is proposed in the present study (equation 3).

It is worth noting that despite the differences in the methodology used, the equation derived in the present study is in good agreement with the equations that were proposed by previous researchers. Figure 5 (right part) shows the log-log plot of seismic moment, $M_{0}$, versus corner frequency, $f_{c}$. The results of Chouliaras and Stavrakakis (1997), Panagiotou (2001), Polatidis (2001), Roumelioti et al. (2002), and Margaris and Hatzidimitriou (2002) are also shown in these figures. The solid line in Figure 6 corresponds to equation defined in the present study. The lines in Figure 10 correspond to the relation between seismic moment, Mo, and corner frequency, $f c$, as proposed by Aki (1988), by Chouliaras and Stavrakakis (1997) and in this study. It appears also from the same figure that the values of the corner frequency obtained in the present study are relatively higher compared to those reported in previous studies for the Aegean area. This difference may be attributed to the different methods that were used to calculate corner frequency in these studies. However, the corner frequencies determined independently by Margaris and Hatzidimitriou (2002) (applying Andrews (1986) method) are in very good agreement with our results.

\section{ACKNOWLEDGEMENTS}

This work was partly funded by the EC project EVG1-CT2001-00040.

\section{REFERENCES}

Aki, K., 1988. Physical theory of earthquakes, Proc. Summer School of EMSC \& IPGS - Strasbourg 1986, Seismic Hazard in Mediterranean Regions (Eds: Bonnin J., Cara A., Cisternas A. and Fantechi R.), pp. 3 -33.

Ambraseys, N., 1999. Early earthquakes in the Kozani area, northern Greece, Tectonophysics 308, 291 - 298. 
Anderson, J. and Hough, S., 1984. A model for the shape of the Fourier amplitude spectrum of acceleration at high frequencies, Bull. Seism. Soc. Am. 74 (5), 1969-1993.

Andrews, D. J., 1986. Objective determination of source parameters and similarity of earthquakes of different size, in Earthquake Source Mechanics, S. Das, J. Boatwright and C. H. Scholz (Editors), American Geophysical Monograph 37, $259-267$.

Archuletta, R. J., Granswick, E., Mueller, C., and Spudich, P., 1982. Source parameters of the 1980 Mammoth Lakes, California, earthquake sequence, J. Geophys. Res. 87 (B6), 4595 - 4607.

Archuletta, R. J., Seale S. H., Sangas P. V., Baker L. M. and Swain S. T., 1992. Garner Valley downhole array of accelerometers instrumentation and preliminary data analysis, Bull. Seism. Soc. Am. 82 (4), 1592 - 1621.

Baskoutas, I., Stavrakakis G., Kalogeras I., 1998. Q factor estimation from the aftershock sequence of the 13 May 1995 Kozani earthquake, J. Geodynamics 26 (2-4), $367-374$.

Boore, M. D. and Boatwright, J., 1984. Average Body-Wave radiation coeficients, Bull. Seism. Soc. Am. 74 (5), $1615-1621$.

Brune, J. M., 1970. Tectonic stress and the spectra of seismic shear waves from earthquakes, J. Geophys. Res 75 (23), $4997-5009$.

Brune, J. N., 1971. Correction, J. Geophys. Res. 76 (20), 5002.

Christaras, B., Dimitriou A. and Lemoni H., 1998. Soil quality as a factor of the distribution of damages at the meizoseismal area of the Kozani-Grevena 1995 earthquake, in Greece $\left(M_{w}=6.6\right)$, J. Geodynamics 26 (2-4), $393-411$.

Chouliaras, G. and Stavrakakis, G. N., 1997. Seismic source parameters from a new dial-up network in Greece Pure and Appl. Geophys. 150, $91-111$.

Drakatos, G., Papanastasiou, D., Voulgaris, N. and Stavrakakis, G, 1998. Observations on the 3-D crustal velocity structure in the Kozani-Grevena (NW Greece) area, J. of Geodynamics, 26, 341-351.

Hatzfeld, D., Nord J., Paul A., Guiguest R., Brione P., Ruegg J-C., Cattin R., Armijjo R., Meyer B., Hubert A., Bernard P., Karakostas, V., C. Papaioannou, Papanastasiou D., Veis G., 1995. The Kozani-Grevena (Greece) Earthquake of May $13,1995, M_{S}=6.6$. Preliminary results of a field multidisciplinary survey, Seismological Research Letters 66 (6), 61-70.

Hatzfeld, D., Karakostas, V., Ziazia, M., Selvaggi, G., G., Leborgne, S., Berge, C., Guiguet, R., Paul, A., Voidomatis, P., Diagourtas, D., Kassaras, I, Koutsikos, I., Makropoulos, K., Azzara, R., Di Bona, M., Baccheschi, S., Bernard, P. and Papaioannou C., 1997. The Kozani-Grevena (Greece) Earthquake of 13 May 1995 revisited from a detailed seismological study, Bull. Seism. Soc. Am. 87 (2), 463-473.

Keilis - Borok, V., 1959. On the estimation of the displacement in an earthquake source and of source dimensions, Annali di Geofisica 12, 205 - 214.

Kiratzi, A. A., 1984. Magnitudes scales for earthquakes in Broader Aegean Area, PhD-Thesis, Aristotle University of Thessaloniki: $189 \mathrm{pp}$ (in Greek with an English abstract).

Kiratzi, A. A., 1999. Stress tensor inversion in Western Greece using earthquake focal mechanisms from the Kozani-Grevena seismic sequence, Annali di Geofisica 42 (4), 725-734.

Lee, W. H. K. and Lahr J. C., 1975. HYPO71: a computer program for the determining hypocenter, magnitude and first motion pattern of local earthquakes, U.S. Geol. Surv. Open File Report, 114 pp.

Lermo, J. and Chavez-Garcia F. G., 1993. Site effect evaluation using spectral ratios with only one station, Bull. Seism. Soc. Am. 83 (5), 1574-1594.

Margaris, B. and Hatzidimitriou P., 1997. Source parameters of the Arnea earthquake $M_{S}=5.8$, Based on stochastic simulation method, Proceedings $3^{\text {ou }}$ Hellenic Conference on Geotechnical Engineering, Patra 1997, 1, pp. 535-542 (in Greek with an English abstract).

Margaris, B. N. and Boore, D. M., 1998. Determination of $\Delta \sigma$ and $k_{0}$ from Response spectra of large earthquakes in Greece, Bull. Seism. Soc. Am. 88 (1), 170-182.

Margaris, B. N. and Papazachos, C. B., 1999. Moment - magnitude relations based on strong - motion records in Greece, Bull. Seism. Soc. Am. 89 (2), $442-455$.

Margaris, B. N. and Hatzidimitriou, P. M., 2002. Source Spectral Scaling and Stress Release Estimates Using Strong - Motion Records in Greece, Bull. Seism. Soc. Am. 92 (3), 1040-1059.

Mountrakis, D., Pavlides, S., Zouros, N., Astaras, Th., Chatzipetros, A., 1998. Seismic fault geometry and kinematics of the 13 May 1995 Western Macedonia (Greece) earthquake, J. Geodynamics 26 (2-4), 175-196.

Nakamura, Y., 1989. A method for dynamic characteristics estimation of subsurface using microtremor on the ground surface, QR Railway Tech. Res. Inst., 30 (1), 25-33.

Panagiotou, M., 2001. Source parameters, fault plain solution and inversion of stress tensor for earthquakes in Northern and Central Aegean, M.Sc., Aristotle University of Thessaloniki: $130 \mathrm{pp}$ (in Greek with an English abstract).

Papanastasiou, D., Drakatos, G., Voulgaris, N. and Stavrakakis, G, 1998. The May 13, 1995 Kozani-Grevena (NW Greece) earthquake: Source study and its tectonic implications, J. of Geodynamics, 26, 233-244.

Papazachos, B. C. and Papazachou, C., 1997. The earthquakes of Greece, Ziti Publ. Co., 304 pp. 
Papazachos, B. C., Kiratzi, A. A., and Karakostas, B. G., 1997. Toward a homogeneous moment-magnitude determination for earthquakes in Greece and the surrounding area, Bull. Seism. Soc. Am. 87 (2), 474-483.

Papazachos, B. C. and Papazachou, C., 2002. The earthquakes of Greece, Ziti Publ. Co., 317 pp (in Greek with an English abstract).

Papazachos, B. C., Karakostas, V. G., Kiratzi, A. A., Papadimitriou E. E., Papazachos, C., 1998. A model for the 1995 Kozani- Grevena seismic sequence, J. Geodynamics 26 (2-4), 217-231.

Pavlides, S. 1998. Geologic faults and earthquakes investing the seismogenetic fault that caused the KozaniGrevena 1995 seismic sequence, in Proceedings of the International Conference « The Kozani-Grevena Earthquake of 13 May 1995: a Scientific and Social Approach >>, pp. 169-181 (in Greek).

Polatidis, A., 2001. Estimation of source parameters and S-wave attenuation in Central Greece, M.Sc., Aristotle University of Thessaloniki: $101 \mathrm{pp}$ (in Greek with an English abstract).

Raptakis, D., Tolis S., Lorentzidis K., Pitilakis K., 1997. Comparison of Instrumental and theoretical Study of the seismic Response in the Kozani-Grevena Earthquake, Proceedings $3^{\circ \mathrm{u}}$ Hellenic Conference on Geotechnical Engineering. Patra 1997, 1, pp. 535-542 (in Greek with an English abstract).

Richter, C. F., 1958. Elementary Seismology, W. F. Freeman and Co., San Francisco, California, 758 pp.

Roumelioti, Z., Kiratzi, A., Theodoulidis, N. and Papaioannou C., 2000. A comparative study of a stochastic and deterministic simulation of strong ground motion applied to the Kozani - Grevena (NW Greece) 1995 sequence, Annali di Geofisica 43 (5), 951-966.

Roumelioti, Z., Kiratzi, A., Theodoulidis, N. and Papaioannou C., 2002. S - wave analysis of the $1995 \mathrm{Kozani}-$ Grevena (NW Greece) aftershock sequence, Journal of Seismology 6, 219-236.

Scordilis, M., 1985. Microseismic study of the Servomacedonian zone and the surrounding area, PhD., Aristotle University of Thessaloniki: $250 \mathrm{pp}$ (in Greek with an English abstract).

Tapley, C. W. and Tull E. J., 2000. Seismic analysis coder, Lawrence Livermore National Laboratory.

Theodulidis, N. and Bard P-Y., 1995. Horizontal to vertical spectral ratio and geological conditions. An analysis of strong motion data from Greece and Taiwan (SMART-1), Soil Dynamics and Earthquake Engineering 14, 177-197.

Theodulidis, N., Lekidis V., Margaris B., Papazachos C., Papaioannou Ch. and Dimitriou P., 1998. Seismic hazard assessment and design spectra for the Kozani-Grevena region (Greece) after the earthquake of May 13, 1995, J. Geodynamics 26 (2-4), 375-391. 